\title{
A Revised Capsule Design for the Accelerated Testing of Advanced Reactor Fuels
}

\section{August 2018}

Geoffrey Beausoleil, Bryon Curnutt, Gary Povirk

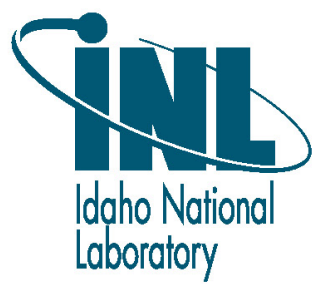




\section{DISCLAIMER}

This information was prepared as an account of work sponsored by an agency of the U.S. Government. Neither the U.S. Government nor any agency thereof, nor any of their employees, makes any warranty, expressed or implied, or assumes any legal liability or responsibility for the accuracy, completeness, or usefulness, of any information, apparatus, product, or process disclosed, or represents that its use would not infringe privately owned rights. References herein to any specific commercial product, process, or service by trade name, trade mark, manufacturer, or otherwise, does not necessarily constitute or imply its endorsement, recommendation, or favoring by the U.S. Government or any agency thereof. The views and opinions of authors expressed herein do not necessarily state or reflect those of the U.S. Government or any agency thereof. 


\section{A Revised Capsule Design for the Accelerated Testing of Advanced Reactor Fuels}

Geoffrey Beausoleil, Bryon Curnutt, Gary Povirk

August 2018

Idaho National Laboratory

Idaho Falls, Idaho 83415

http://www.inl.gov

Prepared for the

U.S. Department of Energy

Under DOE Idaho Operations Office

Contract DE-AC07-05ID14517 


\section{A Revised Capsule Design for the Accelerated Testing of Advanced Reactor Fuels \\ Nuclear Technology \\ Research and Development}

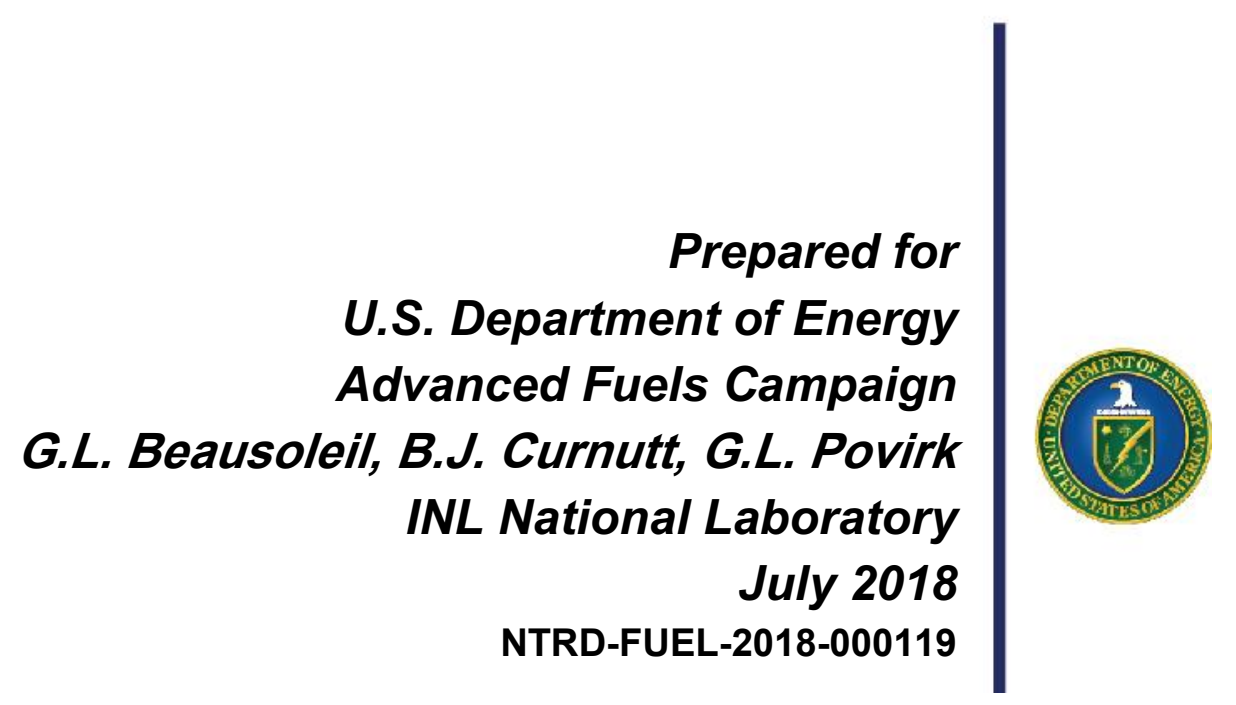




\section{DISCLAIMER}

This information was prepared as an account of work sponsored by an agency of the U.S. Government. Neither the U.S. Government nor any agency thereof, nor any of their employees, makes any warranty, expressed or implied, or assumes any legal liability or responsibility for the accuracy, completeness, or usefulness, of any information, apparatus, product, or process disclosed, or represents that its use would not infringe privately owned rights. References herein to any specific commercial product, process, or service by trade name, trade mark, manufacturer, or otherwise, does not necessarily constitute or imply its endorsement, recommendation, or favoring by the U.S. Government or any agency thereof. The views and opinions of authors expressed herein do not necessarily state or reflect those of the U.S. Government or any agency thereof 


\section{SUMMARY}

Testing of fast reactor fuel is currently challenging because of the thermal neutron spectrum of the Advanced Test Reactor (ATR) and the fact that ATR coolant is substantially below typical temperatures found in liquid metal-cooled fast reactors. Despite these issues, since 2003 the Idaho National Laboratory (INL) has successfully tested a variety of metallic, oxide, and nitride fuels for fast reactor applications. There are, however, opportunities to improve the experiments so that the time required to reach a desired burnup can be reduced, and so the sensitivity of the experiments to fabrication tolerances can be minimized.

A revised capsule design exploits the use of smaller diameter rodlets to increase power densities and correspondingly reduce the irradiation time required to reach high burnup. Thermal and nuclear analyses indicate that the time to reach 30 at $\%$ burnup could be reduced from about 12 years to approximately 2-3 years if the fuel diameter is reduced by one-half and to around 1-2 years if the diameter is reduced by one-third. In addition, reducing fuel diameter improves the radial power distribution in the fuel without the use of cadmium shrouding. This observation opens up the possibility of testing advanced reactor fuel systems in Small I locations in the ATR where there is substantial unused capacity.

Although not directly tied to a revised capsule design, post-irradiation furnace testing is proposed to provide time-to-failure data that will be helpful in the benchmarking of fuel performance models and in assessing the performance of new fuel designs relative to more standard fast reactor fuel systems. In this paradigm, ATR irradiation experiments will be viewed more as preparation for furnace testing than as experiments that exist in isolation. An added benefit to furnace testing is that uncertainties in temperatures will significantly be reduced relative to non-instrumented capsules in the ATR. The time and cost in developing this experimental capability is expected to be reduced considerably because of the availability of the blister anneal furnace used by the HPRR program.

A key issue in the experiment approach is the potential for non-prototypical rodlet dimensions to influence the observed performance of a given fuel design. For example, a qualitative assessment indicates that the effects of fuel-cladding chemical interactions during furnace testing might be more pronounced in reduced diameter rodlets simply because thinner cladding would be more sensitive to a given depth of fission product penetration. In a traditional empirically-driven approach to fuel qualification, any change from prototypical behavior is undesirable because the resulting data cannot easily be assimilated into a statistical correlation. However, in the current approach, systematic variations in fuel diameter provide the opportunity to benchmark fuel performance models over a wider range of parameter space, which in turn is expected to improve understanding and result in better, more physicallybased models in the long term. 

July 2018

INTENTIONALLY BLANK 


\section{ACKNOWLEDGEMENTS}

The authors are pleased to acknowledge helpful discussions with Doug Dempsey, Randy Fielding, Jason Harp, Steve Hayes, and Nate Oldham. 
INTENTIONALLY BLANK 


\section{CONTENTS}

SUMMARY iii

ACKNOWLEDGEMENTS. V

ACRONYMS $\mathrm{xi}$

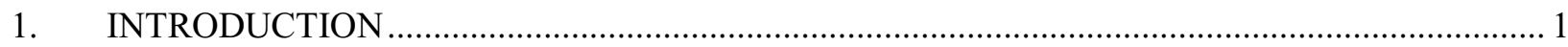

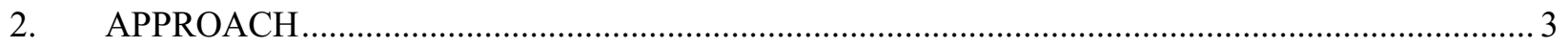

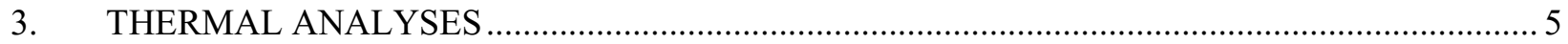

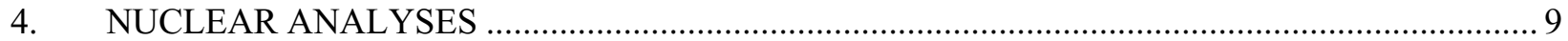

5. OTHER POTENTIAL LENGTH SCALE EFFECTS ASSOCIATED WITH REDUCED

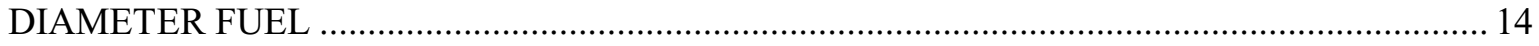

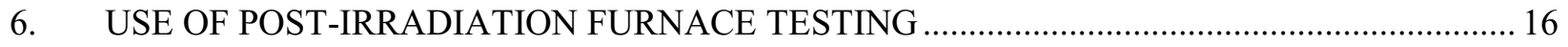

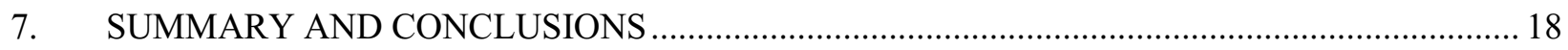

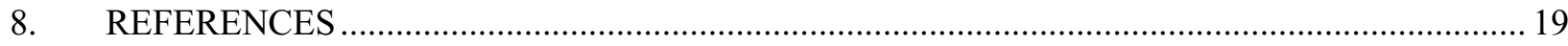

\section{FIGURES}

Figure 1. Schematic of a planar view of the current capsule and basket design. Note the tight helium-filled gap (51 microns) between the capsule and the rodlet and the cadmium liner within the basket. The small gas gap is used to raise fuel and cladding temperatures to prototypical levels. The cadmium liner is provided to filter out thermal neutrons so that the radial power distribution within the fuel is similar to what is expected in an actual fast reactor.

Figure 2. Examples of (a) longitudinal and (b) cross-sectional metallography of a sodium-bonded, $75 \%$ smear density, U-10Zr fuel pin (rodlet 5 from the AFC-4A experiments) tested with the current capsule design. The region with large porosity is evidence of uranium forming an alloy with iron from the cladding that has a low melting point eutectic; this observation in turn indicates that inner cladding temperatures reached at least 650$700^{\circ} \mathrm{C}$. The asymmetric nature of the eutectic formation also suggests that the elevated temperatures were caused in part by eccentric placement of the rodlet within the capsule. [Images are courtesy of Jason Harp of INL.]

Figure 3. Schematic of fuel (in red) surrounded by an arbitrary number of concentric cylinders comprised of materials with potentially different thermal conductivities. The solution for the interface temperatures Ti, the peak inner clad temperature PICT, and the peak central temperature PCT are given in terms of fuel liner heat generation rate LHGR (or fuel power density Q), the radii of the cylinders ri and the material thermal conductivities ki. Note that if the fuel power is characterized in terms of linear heat generation rate and if the geometry is scaled uniformly (e.g., rinew $=$ ariold, where a is a scaling factor), the temperatures reached in all of the cylinders remain unchanged. 
Figure 4. Schematic drawings of (a) a planar view; and (b) an axial view of a double encapsulated design. The dimensions are at this point notional, though the outer capsule diameter will be fixed based on the current capsule designs used in either the AFC series of experiments ( $7.2 \mathrm{~mm}$ or 0.284 ") or the ATF-1 experiments (11 mm or 0.432 "). A key feature of the design is smaller than prototypical rodlet diameters that allow for higher power density in the fuel.

Figure 5. Solid models that are used for thermal analyses of the double-encapsulated experiments. Generation of the models is performed by a Python-based script so that the time required to perform the analyses is dramatically reduced. The development of the script is an example of ongoing efforts to reduce the time and cost needed for design and analyses of irradiation experiments.

Figure 6. Initial models that were generated to compare a standard capsule design with a few different double-encapsulated designs. The linear heat generation rates that are shown were set so that the peak inner liner temperature were approximately the same. Rodlet diameters, helium gap thickness, and eccentricities in inner capsule location were varied to get a better understanding of the effect of these variables on fuel and cladding temperatures.

Figure 7. Example of a double-encapsulated experiment design with (a) a 25 micron eccentricity in the position of the inner capsule and rodlet; and (b) the resulting asymmetry on the temperature distribution within the experiment. The intent in these studies is to assess the sensitivity of the design to fabrication tolerances.

Figure 8. Although thermal analyses of double-encapsulated designs indicate the potential to substantially increase fuel power density, these increases require an increase in fuel enrichment and, in some cases, removal of the cadmium basket. Figure (a) shows the radial power factor as a function of normalized radius for fuel systems that use $75 \%$ smear density, 93 percent U-10Zr. Four cases were considered: (1) full diameter with Cd basket; (2) full diameter, no Cd basket; (3) one-half diameter, no Cd basket; (4) onethird diameter, no Cd basket. The results show that the one-third diameter case with no cadmium basket has a similar distribution in radial power as the full diameter case with a cadmium basket. Figure (b) shows similar results for fuel rods with $60 \%$ smear density and pure uranium metal.

Figure 9. Plot of radial power factor as a function of normalized radius for a fuel pin of $1 / 3$ nominal diameter with 60 percent smear density, pure uranium fuel. Compared to the effects of fuel diameter (see Figure 6), enrichment has a relatively modest effect on the distribution of power within the fuel.

Figure 10. Schematic cross-sectional views of a variety of fuel system designs that are under consideration for testing (the figures are approximately to scale). The reference fuel design (solid fuel slug, 75\% smear density, U10Zr alloy, sodium-bonded) will be used as a basis for comparison to advanced fuel designs during post-irradiation furnace testing. 


\section{TABLES}

Table 1. Predicted Temperatures for Different Capsule Designs............................................................ 9

Table 2. Parameters Used to Study Effect of Diameter on Radial Power Distribution. ............................ 10

Table 3. Parameters Used to Study Effect of Enrichment on Radial Power Distribution.......................... 10

Table 4. Parameters Used to Study Achievable Power Densities........................................................... 10

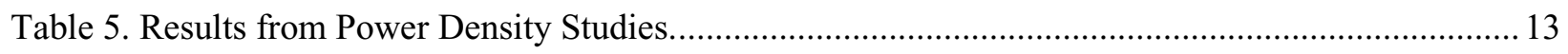


INTENTIONALLY BLANK 


\section{ACRONYMS}

AFC Advanced Fuels Campaign

ATF Accident Tolerant Fuel

ATR Advanced Test Reactor

EBR-II Experimental Breeder Reactor II

FFTF Fast Flux Test Facility

HFEF Hot Fuel Examination Facility

HPRR High Performance Research Reactor

INL Idaho National Laboratory

LHGR linear heat generation rate

MCNP Monte Carlo N-Particle

PICT peak inner clad temperature 

July 2018

INTENTIONALLY BLANK 


\section{A REVISED CAPSULE DESIGN FOR THE ACCELERATED TESTING OF ADVANCED REACTOR FUELS}

\section{INTRODUCTION}

Testing of fast reactor fuel is currently challenging because of the thermal neutron spectrum of the Advanced Test Reactor (ATR) and the fact that ATR coolant is substantially below typical temperatures found in liquid metal-cooled fast reactors. Despite these issues, since 2003 the Idaho National Laboratory (INL) has successfully tested a variety of metallic, oxide, and nitride fuels for fast reactor applications [1] There are, however, opportunities to improve the experiments so that the time required to reach a desired burnup can be reduced, and so the sensitivity of the experiments to fabrication tolerances can be minimized.

The basic approach has been to insert a small test rodlet, notionally 6" long and 0.230 " in diameter, within a stainless steel capsule. A helium-filled gap between the rodlet and capsule raises cladding temperatures from ATR coolant temperatures to levels that are prototypical for a sodium-cooled fast reactor (see Figure 1). The capsule, in turn, sits within an aluminum and cadmium holder (commonly referred to as the "cadmium basket"), and ATR coolant flows through passages in the basket to cool the capsule and test rodlet. The combination of higher enrichments and the use of the cadmium basket allows the designer of the experiment to set desired linear heat generation rates while also having a near-prototypical radial distribution of power within the fuel [1].

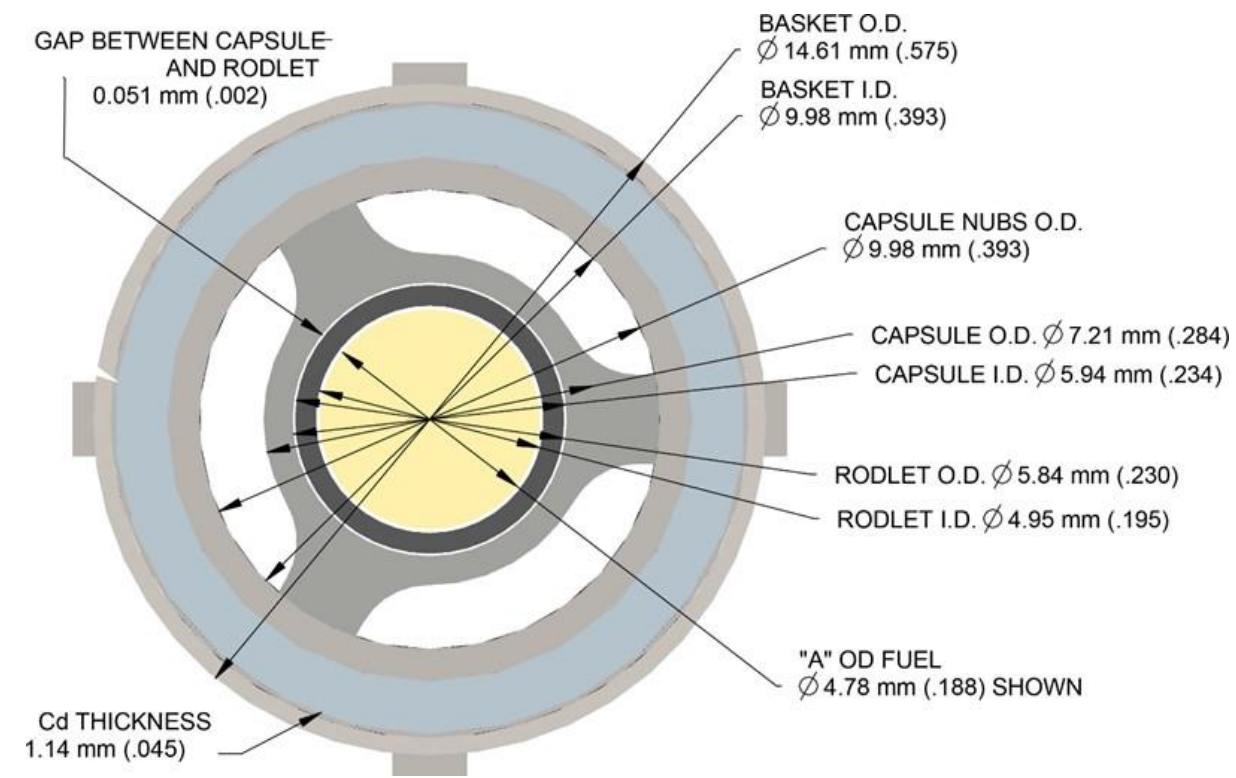

Figure 1. Schematic of a planar view of the current capsule and basket design. Note the tight heliumfilled gap (51 microns) between the capsule and the rodlet and the cadmium liner within the basket. The small gas gap is used to raise fuel and cladding temperatures to prototypical levels. The cadmium liner is provided to filter out thermal neutrons so that the radial power distribution within the fuel is similar to what is expected in an actual fast reactor.

Comparisons in fast reactor fuel behavior have been performed between tests conducted in the ATR and corresponding experiments performed in actual fast reactors. These comparisons show that ATR irradiations performed using cadmium shrouding can be used in the development and testing of fast reactor fuels, although the investigations should be limited to those fuel performance phenomena that are 
primarily dependent on the conditions of temperature and/or temperature gradient within the fuel. These conclusions were supported by an external peer reviewer, who stated: "The data comparisons and analysis show that the ATR irradiations with the cadmium shroud system is sufficiently prototypic that it can be used to develop fast reactor fuels with confidence." [1]

Despite these successes, there remain substantial difficulties with the current experimental approach. The tight helium-filled gap (50 microns or 0.002") makes the temperature a strong function of fabrication tolerances. Figure 2 shows an example of asymmetry in fuel microstructure (and, by extension, fuel temperatures) that was likely induced by a small amount of bow or eccentricity in the rodlet or capsule. In addition, at the current power levels, the time required to reach desired burnup levels (notionally about 30 at $\%$ for U-10Zr fuel) is on the order of about a decade, assuming that the ATR achieves 200 effective full power days per year. Obviously, long irradiation times represent a major impediment to developing advanced fuel systems in an expeditious manner. Finally, because the fast neutron flux in the ATR is roughly an order of magnitude lower than typical flux levels found in a fast-spectrum reactor, the mechanical response of the cladding will not be prototypical. This issue makes the integrated response of the fuel system difficult to assess.

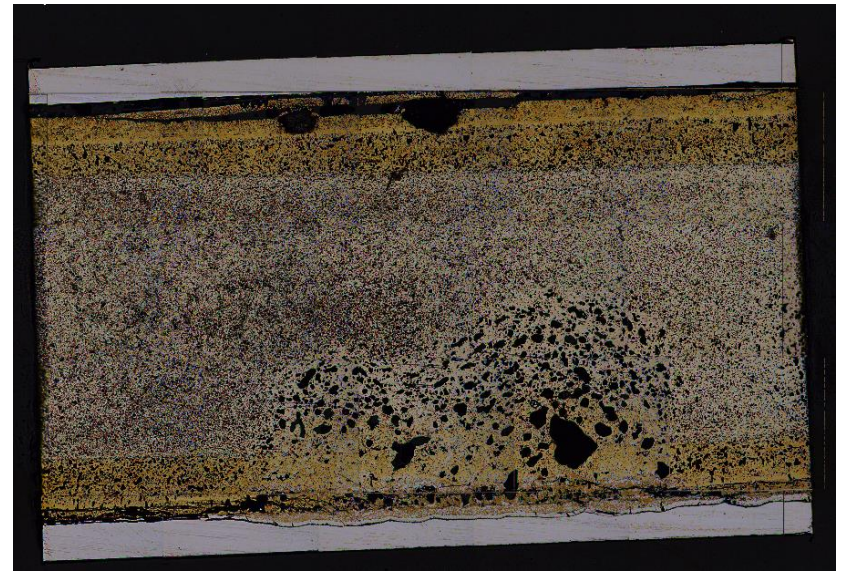

(a)

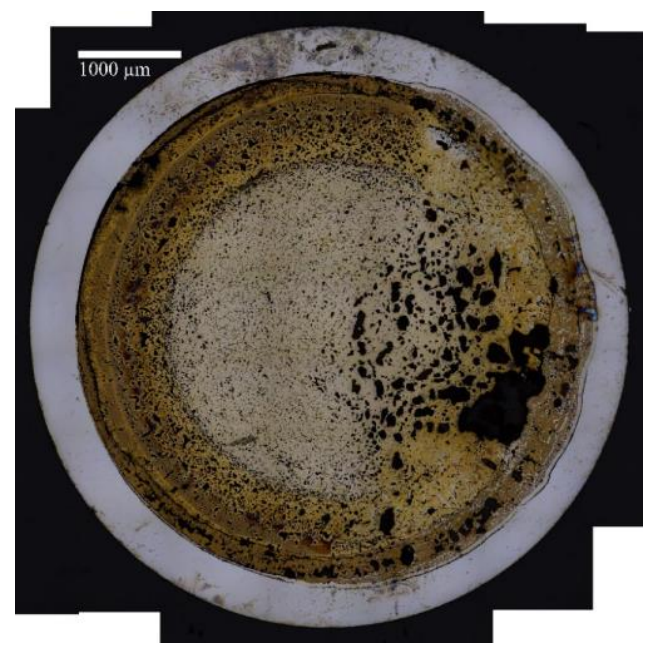

(b)

Figure 2. Examples of (a) longitudinal and (b) cross-sectional metallography of a sodium-bonded, 75\% smear density, U-10Zr fuel pin (rodlet 5 from the AFC-4A experiments) tested with the current capsule design. The region with large porosity is evidence of uranium forming an alloy with iron from the cladding that has a low melting point eutectic; this observation in turn indicates that inner cladding temperatures reached at least $650-700^{\circ} \mathrm{C}$. The asymmetric nature of the eutectic formation also suggests that the elevated temperatures were caused in part by eccentric placement of the rodlet within the capsule. [Images are courtesy of Jason Harp of INL.]

Over the past year, a variety of alternative capsule designs were explored with the following design goals in mind:

1. Increase fuel power density to reduce the time required to reach a given burnup;

2. The design should not require the qualification of new materials;

3. The behavior of the experiment should be sufficiently well-understood so that no out-of-reactor testing is required;

4. The design should be less sensitive to fabrication tolerances;

5. Ideally, the revised experiment should use standard capsule and basket designs to limit the amount of required re-analysis; 
6. The experiment should fit into the "Outer A" positions within the ATR since these locations are currently reserved by the Advanced Fuels Campaign (AFC);

7. If possible, the redesign should also be able to take advantage of existing, available capacity in the "Small I" positions.

This report summarizes a revised capsule design that attempts to satisfy the objectives outlined above.

\section{APPROACH}

The general approach in the revised design is to reduce fuel diameter so that power density can be increased while maintaining prototypical temperatures in the cladding and fuel. Figure 3 shows a schematic of fuel surrounded by an arbitrary number of concentric cylinders comprised of materials with potentially different thermal conductivities. Also shown are solutions [2] for temperatures at the interfaces between each of the cylinders and the solution for the peak central temperature of the fuel. A key result from the analytic solutions is: if the fuel power is characterized in terms of the linear heat generation rate and if the geometry is scaled uniformly, the temperatures reached in all of the concentric cylinders remain unchanged. This simple observation has rather profound implications for the design of experiments to test cylindrical fuel rods in the ATR.

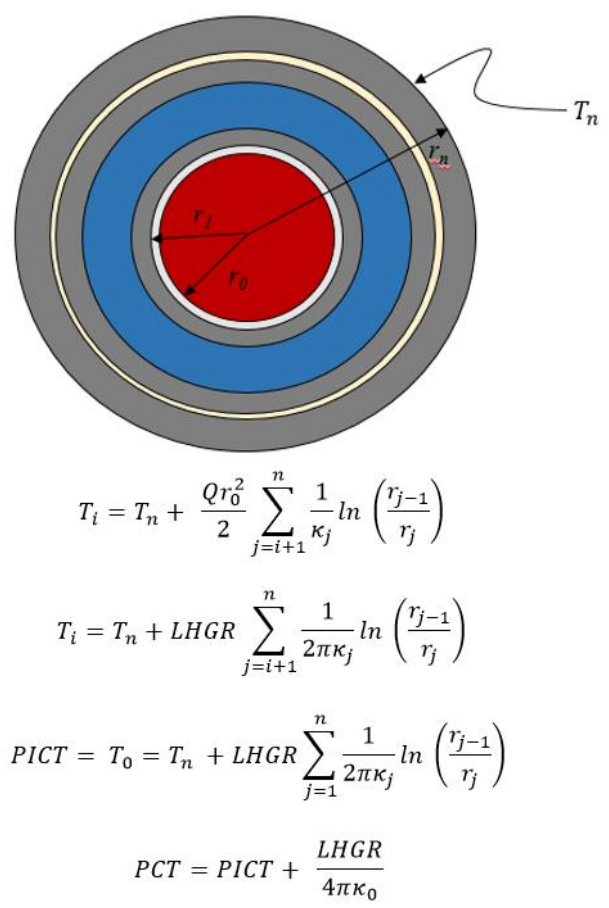

Figure 3. Schematic of fuel (in red) surrounded by an arbitrary number of concentric cylinders comprised of materials with potentially different thermal conductivities. The solution for the interface temperatures Ti, the peak inner clad temperature PICT, and the peak central temperature PCT are given in terms of fuel liner heat generation rate LHGR (or fuel power density $Q$ ), the radii of the cylinders $r_{i}$ and the material thermal conductivities $\kappa_{i}$. Note that if the fuel power is characterized in terms of linear heat generation rate and if the geometry is scaled uniformly (e.g., $r_{i}^{\text {new }}=\alpha r_{i}^{\text {old }}$, where a is a scaling factor), the temperatures reached in all of the cylinders remain unchanged. 
The power density in the fuel, $Q$, is related to linear heat generation rate, $L H G R$, by the expression

$Q=\frac{L H G R}{\pi r_{\text {fuel }}^{2}}$

where $r_{f u e l}$ represents fuel radius. Given the above expression, scaling an experimental design down in size by a factor of three, for example, while maintaining the same linear heat generation rate, results in the same temperature distribution within the fuel and cladding, but with the power density in the fuel increased by a factor of nine. Since the irradiation time to reach a desired burnup is inversely proportional to fuel power density, reducing fuel dimensions by a factor of three could reduce the time for irradiation by almost one order of magnitude. Also note that decreasing fuel pin diameter to increase power density and reduce irradiation times is hardly a novel idea. In 1961, Blake [3] reported results from experiments where fast reactor fuel pin diameters were reduced to 0.122 , which in turn allowed for power densities that achieved 1 at $\%$ burnup for every 17 days of irradiation time (incidentally, Blake was also responsible for suggesting that reducing fuel smear density is a key aspect of improving fast reactor fuel system performance [4]).

A problem that arises in simply scaling the current capsule design to smaller dimensions is that the tolerance issues associated with the tight helium-filled gap would only be exacerbated. This concern led to the double-encapsulated design shown in Figure 4. The helium-filled gap is placed between an inner and outer capsule and liquid sodium is used to thermally bond the inner capsule to the rodlet. The helium gap can be moved toward the periphery of the capsule volume to reduce the heat flux and, everything else being equal, allow for an increase in gap dimensions because the radial heat flux is inversely proportional to the radius. The larger the gap, in turn, the less sensitive the experiment will be to fabrication tolerances; however, analyses have shown that the double-encapsulated design is less sensitive to eccentricities in position of the rodlet and/or inner capsule, so that a helium-filled gap on the order of 50 microns ( 0.002 ") appears to be acceptable. A detailed assessment of the trade-offs between helium gap size, fabrication tolerances, and achievable power densities is beyond the scope of this initial study, but future work will be performed to optimize the dimensions of the experiment. 


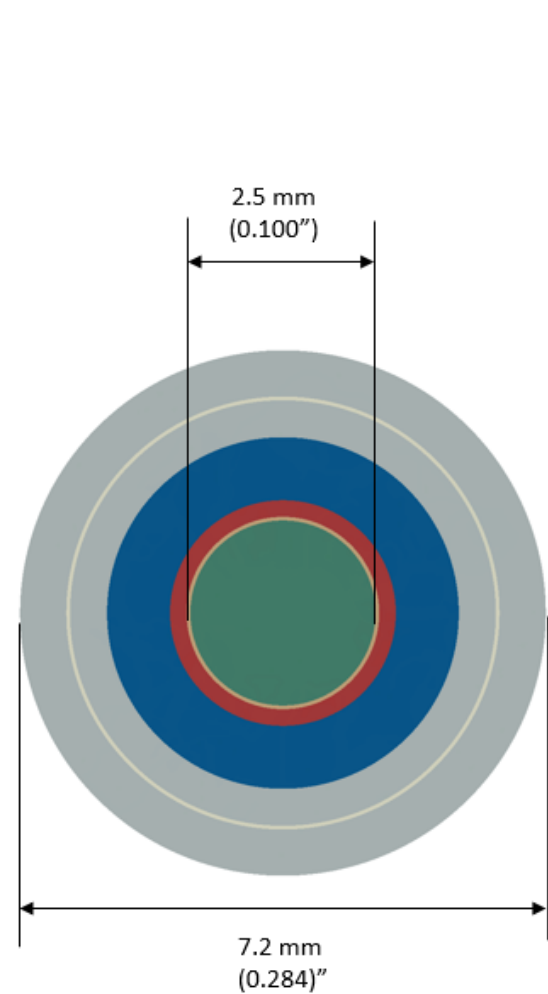

(a)

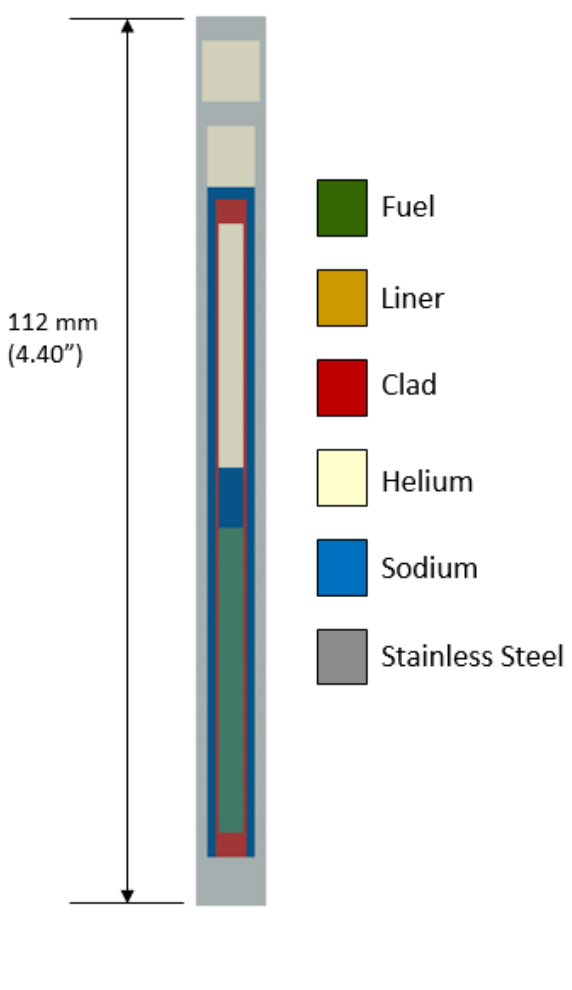

(b)

Figure 4. Schematic drawings of (a) a planar view; and (b) an axial view of a double encapsulated design. The dimensions are at this point notional, though the outer capsule diameter will be fixed based on the current capsule designs used in either the AFC series of experiments (7.2 mm or 0.284") or the ATF-1 experiments (11 mm or 0.432"). A key feature of the design is smaller than prototypical rodlet diameters that allow for higher power density in the fuel.

As noted above, one of the objectives of the revised design was to determine if experiments could be placed not only in the traditional "Outer A" locations but also in the "Small I" locations because of the large number of positions available within Accident Tolerant Fuel (ATF)-1 baskets. Related concerns include whether sufficiently high power densities can be achieved in these locations and whether the radial power distribution within the fuel is acceptable without incorporating cadmium into the basket design. In this regard, another potential advantage of smaller diameter rodlets is that the radial power distribution within the fuel will become more uniform and, thus, more prototypical of actual fast reactor conditions. Nuclear studies have therefore been performed to assess whether acceptable power levels and power distributions can be achieved in the Small I locations without the use of cadmium in the holders.

Finally, note that whether the experiments are destined for an Outer A location or a Small I location, the approach will be to keep the outside diameter of the outer capsule equal to the current outer capsule diameter of either the current AFC experiments (Outer A locations) or the current ATF-1 experiments (Small I locations). In this manner, current basket designs, thermal-hydraulic analyses, and safety related limits on linear heat generation rates can be used without additional analyses.

\section{THERMAL ANALYSES}

All of the thermal analyses performed to evaluate the double-encapsulated design used a Python-based script to automate generation of the finite element models (see Figure 5). While not directly relevant to the primary topic considered here, the development of automation tools is part of an ongoing effort to reduce the time and cost of designing irradiation experiments. 


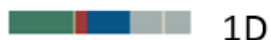

(a)

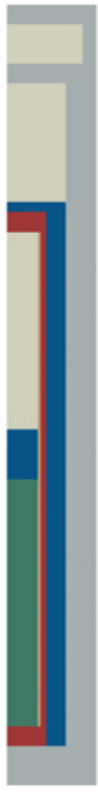

(c)
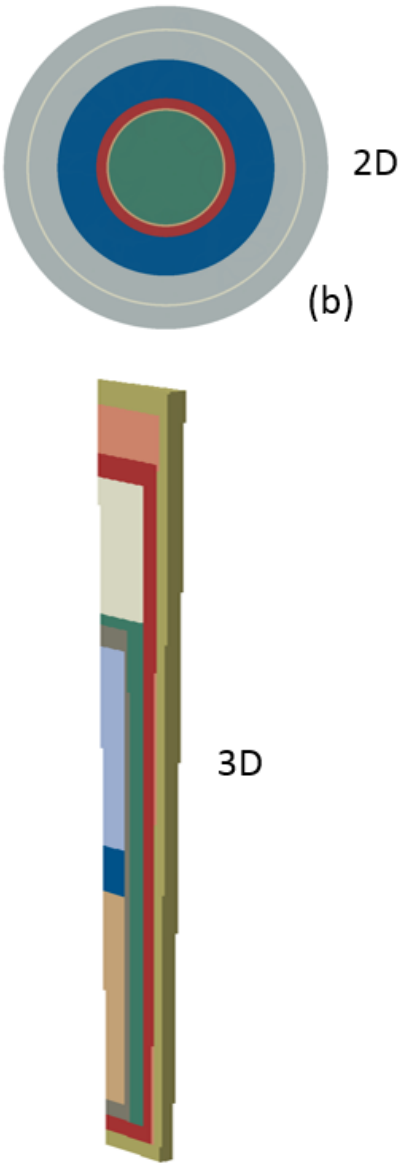

(d)

Figure 5. Solid models that are used for thermal analyses of the double-encapsulated experiments. Generation of the models is performed by a Python-based script so that the time required to perform the analyses is dramatically reduced. The development of the script is an example of ongoing efforts to reduce the time and cost needed for design and analyses of irradiation experiments.

Figure 6 shows four cases that were developed to compare the current capsule design with a standard pin diameter to different variations of double-encapsulated designs with reduced diameter rodlets. The linear heat generation rates in the double-encapsulated cases were set such that the peak inner clad temperature (meaning, in this case, the temperature at the fuel/liner interface) was similar to the standard diameter case of $570^{\circ} \mathrm{C}$. While this peak inner clad temperature is relatively high, the trends and conclusions drawn from the current analyses are not expected to change if the analyses are repeated for a lower target temperature. For all of the capsule designs, analyses were also performed where the rodlet and the inner capsule (if applicable) were shifted by 25 microns ( 0.001 ”) to explore the sensitivity of each design to eccentricities in position. 


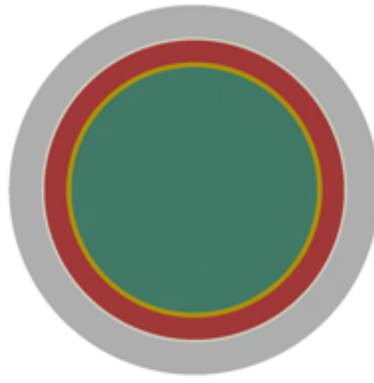

(a)

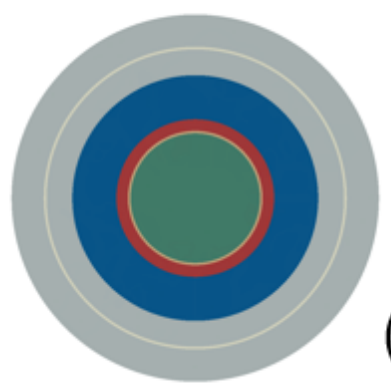

(b)

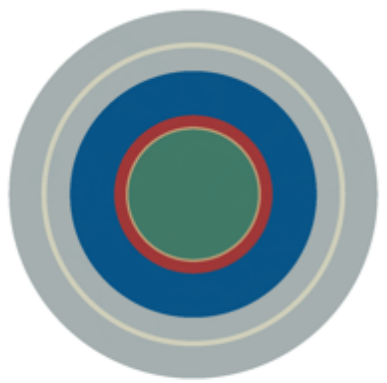

(c)

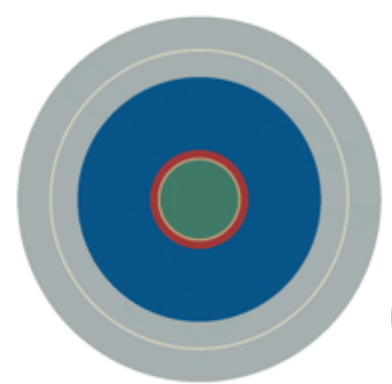

(d)

\section{Case 3}

Double-encapsulated design

$\sim 1 / 2$ standard rodlet diameter $100 \mu \mathrm{m}$ gap

$180 \mathrm{~W} / \mathrm{cm}$

$1.8 \mathrm{X}$ increase in power density
Case 1

Standard capsule design

Standard rodlet diameter

$50 \mu \mathrm{m}$ gap

$365 \mathrm{~W} / \mathrm{cm}$

Fuel

Liner

Clad

\section{Case 2}

Helium

Double-encapsulated design

1/2 standard rodlet diameter

$50 \mu \mathrm{m}$ gap

$300 \mathrm{~W} / \mathrm{cm}$

$2.9 \mathrm{X}$ increase in power density

Stainless Steel
Sodium

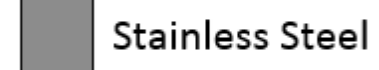

Figure 6. Initial models that were generated to compare a standard capsule design with a few different double-encapsulated designs. The linear heat generation rates that are shown were set so that the peak inner liner temperature were approximately the same. Rodlet diameters, helium gap thickness, and eccentricities in inner capsule location were varied to get a better understanding of the effect of these variables on fuel and cladding temperatures.

For simplicity, the surface temperature of the outer capsule was set to $50^{\circ} \mathrm{C}$ to reflect ATR primary coolant temperatures. In the future, a heat transfer coefficient will be used to account for the difference in temperature between the bulk water and the capsule surface. Expressions for thermal conductivity of 316 stainless steel, helium, sodium, HT9 cladding, zirconium (the assumed liner material), and fuel (assumed to be U-10Zr with 25 percent porosity) were obtained from references [5-10], respectively. 
Figure 7 shows an example of the predicted temperature distribution within an experiment with eccentric positioning, and Table 1 summarizes the results from all of the calculations. In all cases, the double-encapsulated design reduces the change in inner clad temperatures associated with a 25 micron offset. In the double-encapsulated designs, an offset does result in a sometimes significant decrease in inner clad temperature on the cold side of the fuel pin. Interestingly, for the double-encapsulated designs, an offset typically results in a decrease in the inner clad temperature on the hot side of the fuel as well. In contrast, the standard design with an eccentrically placed rodlet shows a significant increase in inner clad temperature on the hot side. The reason for the differing behavior is not readily apparent, but it has been consistently observed in numerous studies. Presumably, the behavior in the double-encapsulated designs is induced by the relatively large distances between the rodlet and the helium gap, or the temperature dependence of thermal conductivity in the sodium bond, or both.
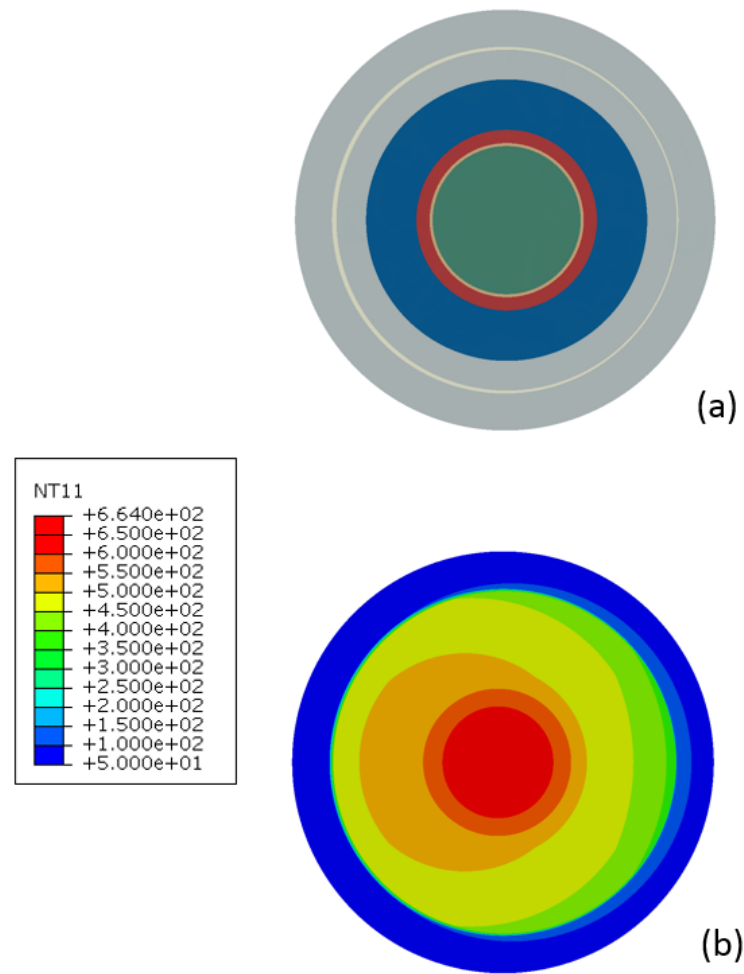

Figure 7. Example of a double-encapsulated experiment design with (a) a 25 micron eccentricity in the position of the inner capsule and rodlet; and (b) the resulting asymmetry on the temperature distribution within the experiment. The intent in these studies is to assess the sensitivity of the design to fabrication tolerances.

The differences in behavior between Cases 2 and 3 shown in Table 1 (Case 2 has a relatively high linear heat generation rate and small helium gap, while Case 3 is the opposite) illustrate the trade-off between fuel power density, gap size, and the sensitivity to eccentric placement. Case 2 has about a $2.9 \mathrm{X}$ increase in power density over the standard design, while Case 3 has a corresponding increase of only about $1.8 \mathrm{X}$. In contrast, however, the larger gap used in case 3 (100 vs. 50 microns) results in predicted temperatures that are much less sensitive to offsets in position. 
Table 1. Predicted Temperatures for Different Capsule Designs.

\begin{tabular}{|c|c|c|c|c|}
\hline Capsule Design & Analyses & $\begin{array}{c}\text { Max. Inner Clad } \\
\text { Temp (C) }\end{array}$ & $\begin{array}{l}\text { Min. Inner Clad } \\
\text { Temp (C) } \\
\end{array}$ & $\begin{array}{l}\text { Peak Fuel } \\
\text { Temp (C) }\end{array}$ \\
\hline \multirow{3}{*}{$\begin{array}{l}\text { Standard } \\
365 \mathrm{~W} / \mathrm{cm} \\
50 \mu \mathrm{m} \text { gap }\end{array}$} & $0 \mu \mathrm{m}$ offset & 572 & 572 & 709 \\
\hline & $25 \mu \mathrm{m}$ offset & 605 & 483 & 695 \\
\hline & Difference & +33 & -89 & -14 \\
\hline \multirow{3}{*}{$\begin{array}{l}\text { Double-Encapsulated } \\
\text { Half-Diameter } \\
300 \mathrm{~W} / \mathrm{cm} \\
50 \mu \mathrm{m} \text { gap }\end{array}$} & $0 \mu \mathrm{m}$ offset & 570 & 570 & 684 \\
\hline & $25 \mu \mathrm{m}$ offset & 567 & 523 & 664 \\
\hline & Difference & -3 & -47 & -20 \\
\hline \multirow{3}{*}{$\begin{array}{l}\text { Double-Encapsulated } \\
\text { Half-Diameter } \\
180 \mathrm{~W} / \mathrm{cm} \\
100 \mu \mathrm{m} \text { gap }\end{array}$} & $0 \mu \mathrm{m}$ offset & 566 & 566 & 637 \\
\hline & $25 \mu \mathrm{m}$ offset & 566 & 556 & 629 \\
\hline & Difference & 0 & -10 & -8 \\
\hline \multirow{3}{*}{$\begin{array}{l}\text { Double-Encapsulated } \\
\text { Third-Diameter } \\
275 \mathrm{~W} / \mathrm{cm} \\
50 \mu \mathrm{m} \text { gap }\end{array}$} & $0 \mu \mathrm{m}$ offset & 572 & 572 & 677 \\
\hline & $25 \mu \mathrm{m}$ offset & 559 & 536 & 656 \\
\hline & Difference & -13 & -36 & -21 \\
\hline
\end{tabular}

Similarly, differences between Cases 2 and 4 provide an indication of the effect of fuel diameter assuming a fixed helium gap size (Case 2 has a pin diameter rough one-half of nominal, while the diameter of Case 4 is roughly one-third that of nominal). Examination of Table 1 shows that the sensitivity of inner clad temperatures to eccentricities in position are roughly similar for both cases. The one-third diameter case, however, has a big advantage in power density, with a $2.5 \mathrm{X}$ increase over the one-half diameter case and a 7.2X increase over the full diameter case at approximately the same nominal inner clad temperature.

Note, however, these analyses implicitly assume that the power densities used in the thermal calculations can actually be achieved in the ATR. To explore whether these powers are achievable and whether the distribution of power within the fuel is acceptable, Monte Carlo analyses were performed using Monte Carlo N-Particle (MCNP).

\section{NUCLEAR ANALYSES}

Nuclear analyses were performed to address the following issues:

1. The effect of fuel diameter and the use of cadmium shrouding on radial power distribution in a small I position,

2. The effect of fuel enrichment on radial power distribution in a small I position, and

3. The effect of core location, cadmium shrouding, and fuel diameter on the achievable power densities within the fuel.

Tables 2 through 4 provide details regarding the assumptions used in the calculations. 
Table 2. Parameters Used to Study Effect of Diameter on Radial Power Distribution.

\begin{tabular}{|c|c|c|c|c|c|}
\hline $\begin{array}{l}\text { Relative } \\
\text { Diameter }\end{array}$ & $\begin{array}{l}\text { Cladding } \\
\text { Outside } \\
\text { Diameter }\end{array}$ & $\begin{array}{l}\text { Reactor } \\
\text { Location }\end{array}$ & Enrichment & $\begin{array}{c}\text { Cadmium } \\
\text { Basket? }\end{array}$ & $\begin{array}{l}\text { Fuel } \\
\text { Alloy }\end{array}$ \\
\hline \multirow{2}{*}{ Full } & \multirow{2}{*}{$0.230 ”$} & \multirow{2}{*}{$\mathrm{I}-21$} & \multirow{2}{*}{$93 \%$} & \multirow{2}{*}{ Yes } & $75 \%$ Smear Density, U-10Zr \\
\hline & & & & & $60 \%$ Smear Density, U \\
\hline \multirow{2}{*}{ Full } & \multirow{2}{*}{$0.230 ”$} & \multirow{2}{*}{$\mathrm{I}-21$} & \multirow{2}{*}{$93 \%$} & \multirow{2}{*}{ No } & 75\% Smear Density, U-10Zr \\
\hline & & & & & $60 \%$ Smear Density, U \\
\hline \multirow{2}{*}{ One-Half } & \multirow{2}{*}{$0.11{ }^{\prime \prime}$} & \multirow{2}{*}{$\mathrm{I}-21$} & \multirow{2}{*}{$93 \%$} & \multirow{2}{*}{ No } & 75\% Smear Density, U-10Zr \\
\hline & & & & & $60 \%$ Smear Density, U \\
\hline \multirow{2}{*}{ One-Third } & \multirow{2}{*}{$0.077 ”$} & \multirow{2}{*}{$\mathrm{I}-21$} & \multirow{2}{*}{$93 \%$} & \multirow{2}{*}{ No } & $75 \%$ Smear Density, U-10Zr \\
\hline & & & & & $60 \%$ Smear Density, U \\
\hline
\end{tabular}

Table 3. Parameters Used to Study Effect of Enrichment on Radial Power Distribution.

\begin{tabular}{|c|c|c|c|c|c|}
\hline $\begin{array}{c}\text { Relative } \\
\text { Diameter }\end{array}$ & $\begin{array}{c}\text { Cladding } \\
\text { Outside } \\
\text { Diameter }\end{array}$ & $\begin{array}{c}\text { Reactor } \\
\text { Location }\end{array}$ & Enrichment & $\begin{array}{c}\text { Cadmium } \\
\text { Basket? }\end{array}$ & $\begin{array}{c}\text { Fuel } \\
\text { Alloy }\end{array}$ \\
\hline One-Third & $0.077 ”$ & I-21 & $30 \%$ & No & $60 \%$ Smear Density, U \\
\hline One-Third & $0.077 ”$ & I-21 & $60 \%$ & No & $60 \%$ Smear Density, U \\
\hline One-Third & $0.077 ”$ & I-21 & $60 \%$ & No & $60 \%$ Smear Density, U \\
\hline
\end{tabular}

Table 4. Parameters Used to Study Achievable Power Densities.

\begin{tabular}{|l|c|c|c|c|l|}
\hline $\begin{array}{c}\text { Relative } \\
\text { Diameter }\end{array}$ & $\begin{array}{c}\text { Cladding } \\
\text { Outside } \\
\text { Diameter }\end{array}$ & $\begin{array}{c}\text { Reactor } \\
\text { Location }\end{array}$ & Enrichment & $\begin{array}{c}\text { Cadmium } \\
\text { Basket? }\end{array}$ & \multicolumn{1}{c|}{$\begin{array}{c}\text { Fuel } \\
\text { Alloy }\end{array}$} \\
\hline Full & $0.230 ”$ & B-5 & $93 \%$ & Yes & $75 \%$ Smear Density, U-10Zr \\
\hline One-Half & $0.115 ”$ & I-21 & $93 \%$ & No & $60 \%$ Smear Density, U \\
\hline One-Third & $0.077 ”$ & I-21 & $93 \%$ & No & $60 \%$ Smear Density, U \\
\hline One-Third & $0.077 ”$ & I-22 & $93 \%$ & No & $60 \%$ Smear Density, U \\
\hline
\end{tabular}

Figure 8a shows the radial power factor (i.e., the actual power density relative to the average power density) as a function of normalized radius for fuel systems that use $75 \%$ smear density, 93 percent enriched U-10Zr. Four cases were considered: (1) full diameter with Cd basket, (2) full diameter, no $\mathrm{Cd}$ basket, (3) one-half diameter, no Cd basket, and (4) one-third diameter, no Cd basket. Figure $8 \mathrm{~b}$ shows quite similar results for fuel rods with $60 \%$ smear density and 93 percent enriched pure uranium metal. As expected, both the use of a cadmium basket and a reduction in fuel diameter result in more uniform power through the fuel. Given that reducing fuel diameter by a factor of three without a cadmium shroud produces a similar distribution of power as the full diameter case with cadmium, it appears that acceptable power distributions can be achieved if the diameter is small enough. 


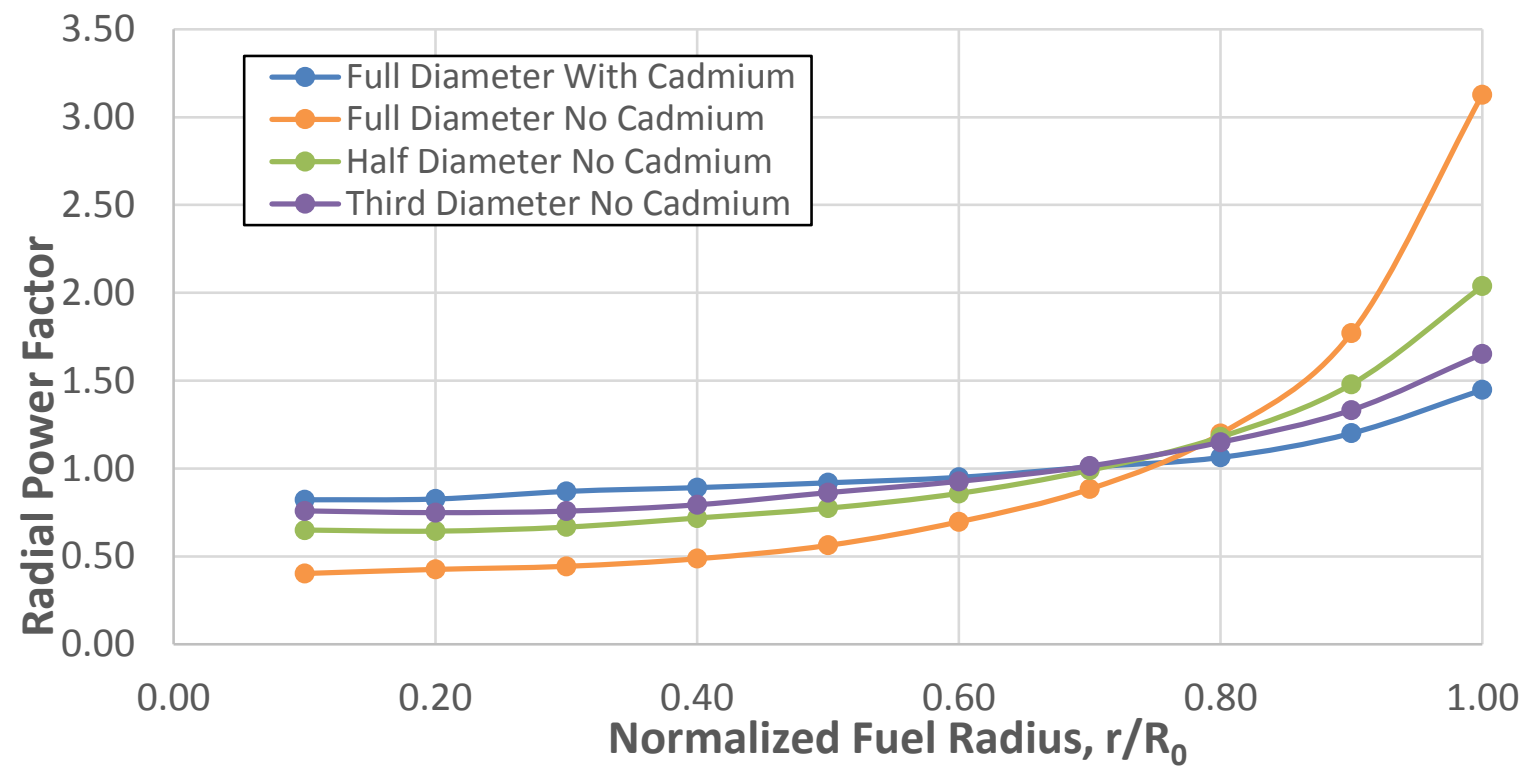

(a)

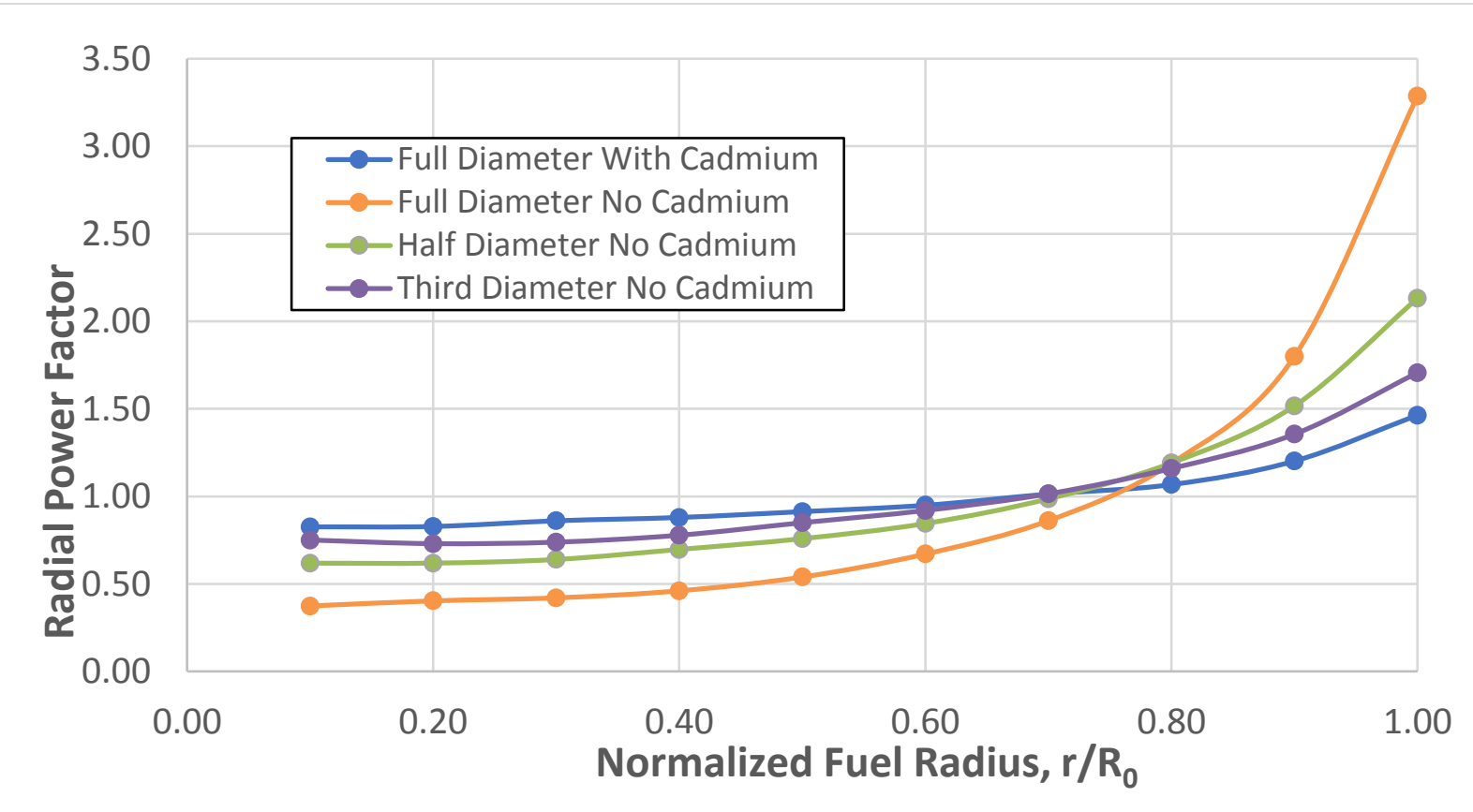

(b)

Figure 8. Although thermal analyses of double-encapsulated designs indicate the potential to substantially increase fuel power density, these increases require an increase in fuel enrichment and, in some cases, removal of the cadmium basket. Figure (a) shows the radial power factor as a function of normalized radius for fuel systems that use $75 \%$ smear density, 93 percent $U-10 Z r$. Four cases were considered: (1) full diameter with Cd basket; (2) full diameter, no Cd basket; (3) one-half diameter, no $C d$ basket; (4) one-third diameter, no Cd basket. The results show that the one-third diameter case with no cadmium basket has a similar distribution in radial power as the full diameter case with a cadmium basket. Figure (b) shows similar results for fuel rods with $60 \%$ smear density and pure uranium metal. 
The effect of enrichment on power distribution is shown in Figure 9 for one-third diameter rodlets using 60 percent smear density, pure uranium fuel. Increasing enrichment results in more self-shielding and, therefore, a more non-uniform distribution of power, but a comparison of Figures 8 and 9 indicates that fuel diameter has a more pronounced effect.

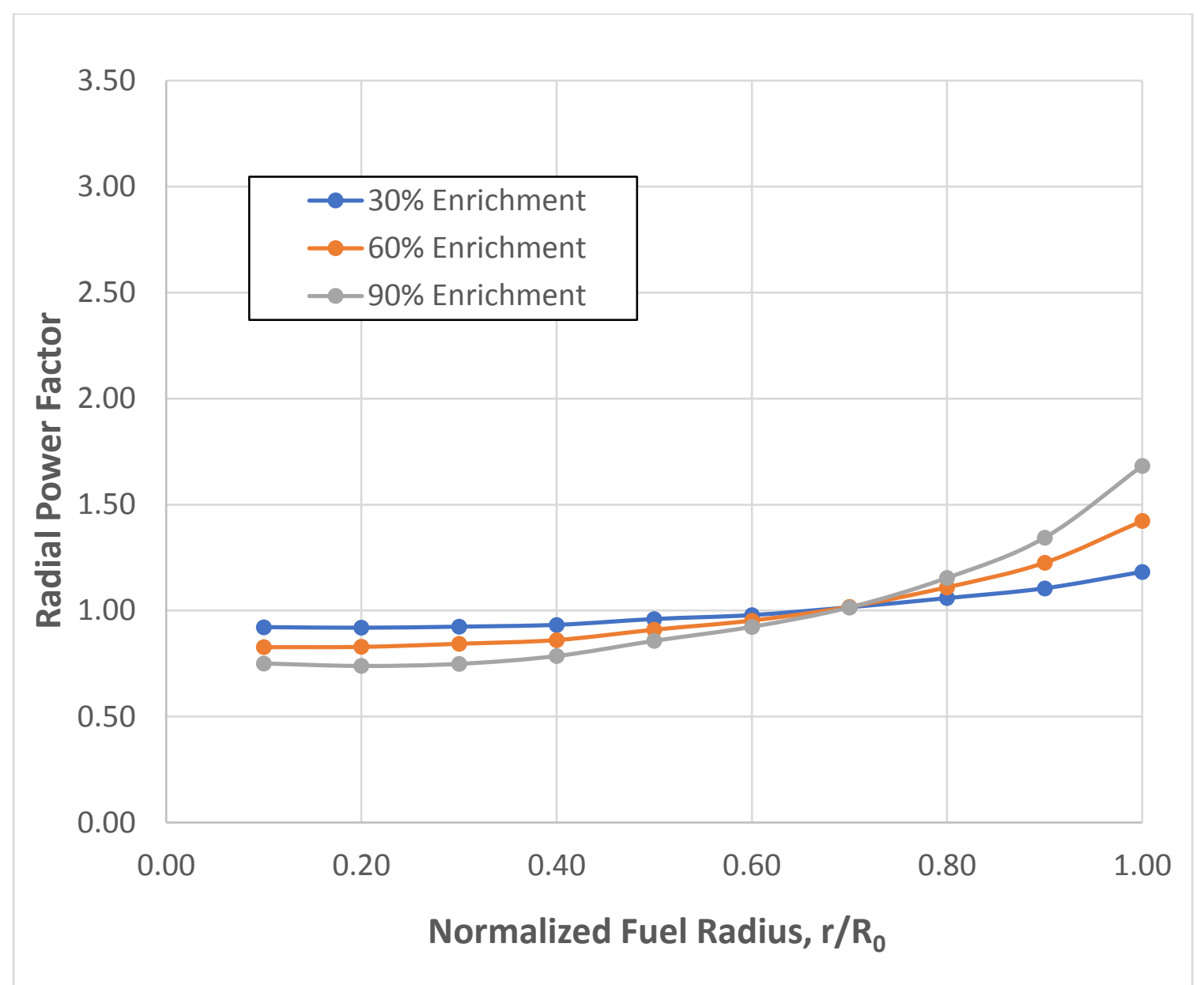

Figure 9. Plot of radial power factor as a function of normalized radius for a fuel pin of 1/3 nominal diameter with 60 percent smear density, pure uranium fuel. Compared to the effects of fuel diameter (see Figure 8), enrichment has a relatively modest effect on the distribution of power within the fuel.

Table 5 provides the results from the studies that examined the magnitude of power densities that can be achieved within the fuel. To provide as much context as possible, the power densities are expressed as either the amount of burnup that could be achieved during a 55 day ATR cycle or in the number of years it would take to achieve a burnup of 30 at\% (assuming 200 effective full power days of ATR operation per year). The most striking result are the comparisons in the time to achieve 30 at $\%$ burnup between the standard case (full diameter with the cadmium basket) and the reduced diameter cases without a cadmium shroud. The full diameter case is expected to require almost 12 years of irradiation time while the reduced diameter cases are predicted to require on the order of 1-2 years for the one-third diameter case and 2-3 years for one-half diameter rodlets. 
Table 5. Results from Power Density Studies.

\begin{tabular}{|l|c|c|}
\hline \multicolumn{1}{|c|}{ Case } & $\begin{array}{c}\text { Burnup (at\%) per 55 day } \\
\text { ATR cycle }\end{array}$ & $\begin{array}{c}\text { Time to Achieve } \\
\text { 30 at.\% Burnup (years) }\end{array}$ \\
\hline $\begin{array}{l}\text { Full Diameter } \\
\text { Small B Position }\end{array}$ & & \\
75\% Smear Density U-10Zr & & 11.7 \\
Cd Basket & & \\
93\% Enrichment & & \\
365 W/cm & & \\
\hline One-Half Diameter & & \\
Northeast Small I Position & & \\
$75 \%$ Smear Density U & 3.6 & \\
No Cd Basket & & \\
$93 \%$ Enrichment & & \\
300 W/cm & & \\
\hline One-Third Diameter & & \\
Northeast Small I Position & & \\
$75 \%$ Smear Density U & & \\
No Cd Basket & & \\
$93 \%$ Enrichment & & \\
180 W/cm & & \\
\hline One-Third Diameter & & \\
Southeast Small I Position & & \\
$75 \%$ Smear Density U & & \\
No Cd Basket & & \\
$93 \%$ Enrichment & & \\
230 W/cm & & \\
\hline
\end{tabular}

The calculations also indicate that for the one-third diameter cases, the linear heat generation rates may be below that which would be acceptable from a thermal perspective. This result suggests that perhaps reducing diameter by as much as a factor of three may be unnecessary from the viewpoint of minimizing irradiation times. However, the added margin before reaching undesirable peak inner cladding temperatures and the more uniform radial power distribution obtained with smaller fuel diameters might indicate that testing one-third diameter pins would still be advantageous.

The half diameter case, which assumed a cladding outside diameter of 0.115 ", was predicted to reach a burnup of 3.6 at $\%$ after a 55 ATR cycle. This burnup rate can be re-expressed as 1.0 at $\%$ per 15 days of irradiation time, which is remarkably close to the results from Blake [3], who reported burnup rates of 1.0 at $\%$ for every 17 days of irradiation time for 0.122 " fuel pins. The results from Blake's work provide confirmation of our analyses that indicate substantial increases in fuel power density can be achieved with reduced diameter fuel pins. 


\section{OTHER POTENTIAL LENGTH SCALE EFFECTS ASSOCIATED WITH REDUCED DIAMETER FUEL}

While the effect of reduced fuel diameters on the thermal and nuclear behavior of the fuel system have been quantitatively explored, it is also worth considering the effects of fuel length scale on the mechanical response of the system and on the potential for changes in cladding degradation caused by fuel/cladding chemical interactions. The intent here is to qualitatively assess issues that could arise with the use of reduced diameter fuel and the potential differences in behavior that could result. In addition, the disadvantages and potential advantages regarding the use of non-prototypical dimensions in developing a more fundamental understanding of fuel system behavior will be discussed.

The stress and strain fields that can develop within a solid body are generally independent of length scale. As a simple, and relevant example, the hoop stress in a thin-walled cylindrical pressure vessel is given by

$\sigma=\frac{P r}{t}$

where $P$ is the internal pressure, $r$ is the radius of the cylinder, and $t$ is its thickness. Obviously, the stresses in the cylinder remain unchanged if thickness and radius are scaled uniformly. There are, however, examples in solid mechanics where length scale effects are important, including problems involving fracture mechanics (i.e., the effect crack size on the stress intensity factor in linear elastic fracture mechanics) and plastic deformation (i.e., the effect of grain size on yield strength, commonly known as the Hall-Petch effect). The deformation behavior of a fuel system, however, should be independent of length scale, assuming that the microstructures of the fuel and cladding remain similar and other phenomena influencing fuel system behavior (i.e., distribution of radial power, fuel and cladding temperatures, amount of gas released from the fuel, etc.) remain unchanged.

Fission gas release is a phenomenon, however, that could be influenced by smaller fuel dimensions. Assuming that the pore distribution and pore sizes remain unchanged in a reduced diameter rodlet, there may be increased connectivity of porosity to the fuel surfaces and, therefore, increased gas release associated with reduced fuel dimensions. Since gas release is a key aspect of metallic fuel behavior, any significant change in the amount of gas release would be expected to impact performance.

Fuel-cladding chemical interactions is also an area where there may be important effects of length scale. In the fuel itself, shorter diffusion distances and higher temperature gradients will likely accelerate the transport of alloying elements [11] and fission products. This acceleration is not expected to result in a substantial change in fuel behavior, however, because constituent redistribution generally occurs relatively rapidly even at prototypical power densities. Conversely, the increase in the fuel surface areato-volume ratio as fuel diameter decreases may be expected to have an impact on fuel/cladding chemical interactions. For a given fission density and with an increase in the relative amount of surface area, the concentration of fission products at the fuel/cladding interface could be less for reduced diameter rodlets, assuming that there is sufficient time such that the transport of fission products to the interface is essentially independent of diameter.

More of concern, however, is the transport of fission products into the cladding. One simple way to treat this potential issue is to assume a fixed concentration of fission products at the fuel cladding interface (note that an implicit assumption here is that generation and transport of fission products to the fuel/cladding interface is fast, relative to diffusion of material into the cladding). In this case, a characteristic diffusion distance, $x=\sqrt{D t}$, can be obtained from analytic solutions to the diffusion equation [12], where in the present context $x$ is a measure of the depth of penetration of fission products into the cladding, $D$ is the diffusivity, and $t$ is time. From a fuel performance perspective, however, the 
important metric is not fission product penetration depth but the depth of penetration relative to cladding thickness, i.e.,

$\zeta=\frac{x}{l}=\frac{\sqrt{D t}}{l}$

where $\zeta$ is the normalized penetration depth and $l$ is cladding thickness. Now imagine two different rodlets being tested in the ATR: (1) a standard diameter case with a standard fuel power density; and (2) a rodlet with dimensions uniformly scaled by a factor $\alpha$ and where the power density is scaled by a factor of $1 / \alpha^{2}$ so that the linear heat generation rate and the resulting temperatures are similar to the standard case. Note that, for a given desired burnup, the irradiation time is inversely proportional to power density, so that the irradiation time for case 2 is scaled by a factor of $\alpha^{2}$. With these assumptions, the relative penetration depths for each case can be written as

$\zeta_{1}=\frac{\sqrt{D t_{1}}}{l_{1}}$

$\zeta_{2}=\frac{\sqrt{D t_{2}}}{l_{2}}=\frac{\sqrt{D \alpha^{2} t_{1}}}{\alpha l_{1}}=\frac{\sqrt{D t_{1}}}{l_{1}}$

which indicates that the relative amount of in-reactor clad wastage should be essentially independent of rodlet size. Effectively, in the reduced diameter case, the smaller cladding thickness is offset by a decrease in the time for diffusion to occur.

In addition, post-irradiation testing of rodlets in a furnace may provide a means to better assess the performance of a new fuel system relative to the HT9 clad, sodium-bonded, U-10Zr alloy, 75 percent smear density fuel system that was extensively tested in Experimental Breeder Reactor II (EBR-II) and Fast Flux Test Facility (FFTF). In this case, given that the diffusion times will be independent of length scale, the relative penetration depths for each case will take the form

$\zeta_{1}=\frac{\sqrt{D t_{\text {furnace }}}}{l_{1}}$

$\zeta_{2}=\frac{\sqrt{D t_{\text {furnace }}}}{l_{2}}=\frac{\sqrt{D t_{\text {furnace }}}}{\alpha l_{1}}$

Assuming that Case 2 represents a reduced diameter rodlet such that $\alpha<1$, the fission product penetration depth relative to cladding thickness would increase. Further assuming that fuel/cladding chemical interactions are a contributing factor to failure, furnace testing of reduced diameter rodlets could, therefore, lead to a decrease in the time to failure relative to standard diameter fuel pins.

From the above discussions, it appears plausible that the use of non-prototypical fuel pins could result in different behaviors under some conditions. From the viewpoint of a traditional empirical approach to establishing fuel performance limits, any change from prototypical behavior is undesirable because the testing results cannot then be easily used in a simple correlation. However, from the standpoint of qualifying physically-based models, examining fuel system behavior when relevant dimensions are systematically varied provides an opportunity to more rigorously test the validity of a particular theory. Given the myriad of sub-models and associated coefficients that make up an integrated fuel performance model, having the ability to test a wide range of fuel system parameters is essential to ensure that the model is not simply tuned within a restricted parameter space. In addition, the reduced time to accumulate significant burnup should increase the interplay between model development and the design of new experiments, regardless of whether a substantial dependence on length scale is observed. 


\section{USE OF POST-IRRADIATION FURNACE TESTING}

Although not directly tied to the revised capsule design, the other major proposed change to testing of advanced reactor fuel systems is to follow ATR irradiations with furnace testing of rodlets in the Hot Fuel Examination Facility (HFEF). As will be discussed, this approach not only appears feasible at relatively low cost but will also provide valuable data to better assess the performance potential of a given fuel design and to benchmark against model predictions.

There are (at least) two aspects of testing fast reactor fuel systems in the ATR that hinder our ability to fully understand integral fuel system behavior: (1) a large uncertainty in temperatures associated with capsule experiments in the ATR, and (2) the non-prototypical fast neutron flux levels that substantially reduce irradiation-induced creep and swelling in the cladding. To develop better quantitative understanding of fuel performance, the approach will be to use irradiation experiments in ATR as a means for preparing rodlets for testing in a furnace. Furnace testing, in turn, will explore the time and temperature required to induce fuel element failure under relatively well-controlled conditions. Given that irradiation testing will not be intended to directly provide fuel performance data, peak inner clad temperatures during irradiation will be limited so that substantial amounts of fuel/cladding chemical interactions will not be expected. Furthermore, out-of-reactor furnace testing will be performed at temperatures on the order of $650^{\circ} \mathrm{C}$ or greater where the in-reactor mechanical response of the cladding is dominated by thermal creep.

Although the revised capsule design is expected to have somewhat reduced uncertainties in temperature and decreases the risks of having excessively high inner clad temperatures caused by eccentric positioning of the rodlet, a relatively high degree of uncertainty regarding in-reactor temperatures is still expected. Furnace testing will substantially reduce this uncertainty and allow for more conclusive determination of key parameters, e.g., the activation energy for penetration of fission products into the cladding.

Testing fuel systems to failure in a furnace is expected to have a number of advantages beyond reduced uncertainties in temperature. Comparing the deformation and failure times that are observed during furnace testing will provide valuable data to compare against model predictions. Moreover, the approach in test matrix design will be to compare the time-at-temperature behavior of new fuel designs directly against the behavior of standard 75 percent smear density, U-10Zr rodlets to assess whether a revised design can be expected to offer improved performance. In addition, given the complexity of high burnup nuclear fuels, there are any number of scientific studies that could be undertaken to better understand fuel behavior. Taking fuel systems to failure, however, will focus efforts on understanding phenomena that are essential to the development of fuel systems with an expanded performance envelop.

Preliminary discussions with project managers from the High Performance Research Reactor (HPRR) project have indicated that there is substantial excess capacity in an existing furnace within HFEF that is used to induce blisters in irradiated research reactor fuel plates. This furnace is long enough to anneal full-size EBR-II fuel pins and, therefore, can easily accommodate numerous ATR-sized rodlets. In the coming fiscal year, investigations are planned for the design of a vessel that will house rodlets within the furnace, the design of instrumentation that will detect fission gas release from within the vessel, and the design of equipment for automated visual inspection of the rodlets and for automated dimensional measurements. In this manner, the experiments will provide data regarding rodlet deformation over time and the time when specimen failure occurred.

Finally, note that the anticipated reduction in capsule length and the expected ability to use the small I locations implies that the number of rodlets that can be considered for a single ATR insertion can be increased substantially. For example, 63 of the potential 84 positions available within ATF-1 baskets in the small I locations are currently unused and are, for the most part, available for the testing of advanced reactor fuels. Although the exact number of test specimens for the first insertion will be determined in part by fabrication studies on reduced diameter fuel pins, we are, at least initially, targeting on the order of 50 rodlets. Thus, we hope to increase the rate of data collection not only by accelerating burnup but 
also by increasing the number of specimens inserted to the reactor at one time. Also note that a substantial fraction of rodlet fabrication costs are typically in the setup associated with the various steps in the process, i.e., fuel casting, sodium-bonding, end cap welding, etc. By increasing the number of specimens fabricated at a given time, the expectation is that the fabrication cost per rodlet will decrease.

Figure 10 shows a schematic of fuel pin designs that are under consideration for testing. As discussed previously, the current plan is to test both the reference metallic fuel pins and newer designs that will hopefully provide benefits in fabrication (slotted fuel), disposal (annular fuel without bond sodium), uranium loading (pure uranium metal), and/or burnup capabilities (incorporation of liners, reduced smear density designs). Although a preliminary test matrix is not yet in place, it is worth listing some of studies that would be of value:

(1) behavior of slotted vs. annular vs. solid fuel;

(2) sodium vs. helium vs. mechanical bonding;

(3) zirconium vs. vanadium liners;

(4) the evolution of fuel microstructure as a function of burnup;

(5) gas release as a function of burnup;

(6) fuel microstructure after irradiation and after furnace testing;

(7) effects of smear density and plenum size;

(8) effect of fuel diameter;

(9) behavior of U-10Zr vs. pure uranium;

(10) differences in behavior between irradiations with and without a cadmium basket;

(11) HT9 vs. T91 vs. T92 cladding. 


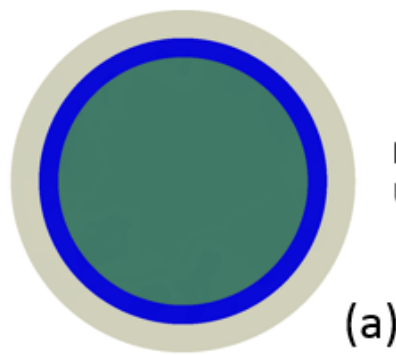

Reference Design: solid fuel slug, $75 \%$ smear density, U10Zr, sodium bond

(a)

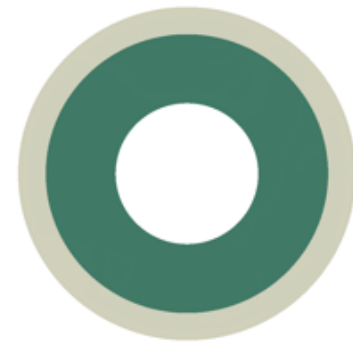

Annular Design: annular fuel slug, $75 \%$ smear density, U10Zr, primarily without sodium bond

(b)

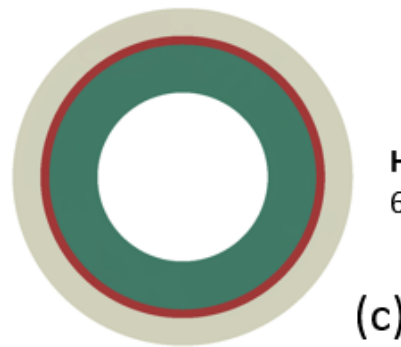

High Burnup Annular Design with Liner: annular fuel slug, $60 \%$ smear density, $U$, primarily without sodium bond

(c)

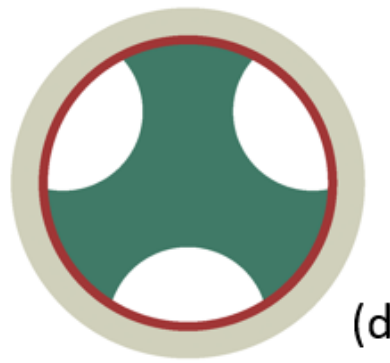

High Burnup Slotted Design with Liner: slotted fuel slug, $60 \%$ smear density, $\mathrm{U}$, primarily with sodium bond

(d)

Figure 10. Schematic cross-sectional views of a variety of fuel system designs that are under consideration for testing (the figures are approximately to scale). The reference fuel design (solid fuel slug, 75\% smear density, U10Zr alloy, sodium-bonded) will be used as a basis for comparison to advanced fuel designs during post-irradiation furnace testing.

Of course, not all of these studies can be pursued, but the exhaustive nature of the list indicates that there is no shortage of valuable tests that could be performed.

\section{SUMMARY AND CONCLUSIONS}

The revised capsule design exploits the use of smaller diameter rodlets to increase power densities and correspondingly reduce the irradiation time required to reach high burnup. Thermal and nuclear analyses indicate that the time to reach $30 \mathrm{at} \%$ burnup could be reduced from about 12 years to approximately 2-3 years if the fuel diameter is reduced by one-half and to around 1-2 years if the diameter is reduced by one-third. In addition, reducing fuel diameter improves the radial power distribution in the fuel without the use of cadmium shrouding. This observation opens up the possibility of testing advanced reactor fuel systems in Small I locations in the ATR where there is substantial unused capacity. 
Although not directly tied to a revised capsule design, post-irradiation furnace testing is proposed to provide time-to-failure data that will be helpful in the benchmarking of fuel performance models and in assessing the performance of new fuel designs relative to more standard fast reactor fuel systems. In this paradigm, ATR irradiation experiments will be viewed more as preparation for furnace testing than as experiments that exist in isolation. An added benefit to furnace testing is that uncertainties in temperatures will significantly be reduced relative to non-instrumented capsules in the ATR. The time and cost in developing this experimental capability is expected to be reduced considerably because of the availability of the blister anneal furnace used by the HPRR program.

A key issue in the experiment approach is the potential for changes in rodlet dimensions to influence the observed performance of a given fuel design. For example, a qualitative assessment indicates that the effects of fuel-cladding chemical interactions during furnace testing might be more pronounced in reduced diameter rodlets simply because thinner cladding would be more sensitive to a given depth of fission product penetration. In a traditional empirically-driven approach to fuel qualification, any change from prototypical behavior is undesirable because the resulting data cannot easily be assimilated into a statistical correlation. However, in the current approach, systematic variations in fuel diameter provide the opportunity to benchmark fuel performance models over a wider range of parameter space, which in turn is expected to improve understanding and result in better, more physically-based models in the long term.

Finally, note that although the present study was restricted to metallic fuel systems for sodium-cooled reactors, the same principles can be used to accelerate burnup in other applications. Though not reported here, recent calculations have shown, not surprisingly, that burnup can be accelerated in light water reactor fuel by reducing fuel rod diameter and increasing enrichment. Such an approach would be complementary to the ATF-2 loop experiments and could be an important aspect in providing enhanced fuel systems to the commercial nuclear industry in a reduced amount of time.

\section{REFERENCES}

[1] Harp, J.M., S.L. Hayes, P.G. Medvedev, D.L. Porter and L. Capriotti, "Testing Fast Reactor Fuels in a Thermal Reactor: A Comparison Report,” INL/EXT-17-61677 (2017).

[2] Carslaw, H.S., and J.C. Jaeger, "Conduction of Heat in Solids," $2^{\text {nd }}$ Edition, (1959).

[3] Blake, L.R., "Irradiation of Uranium Metal and Uranium Oxide Fuel Pins to High Burnup at High Temperature," Reactor Science and Technology 15, (1961).

[4] Blake, L.R., "Achieving High Burnup in Fast Reactors," Reactor Science and Technology 14, (1961).

[5] Hales, J.D. et al., "BISON Theory Manual Release 1.3," INL/EXT-13-29930, Rev. 3, p. 26 (2016).

[6] Petersen, H., "The Properties of Helium," Danish Atomic Energy Commission Riso Report No. 224 p. 29 (1970).

[7] Fink, J. K., and L. Leibowitz, "Thermodynamic and Transport Properties of Sodium Liquid and Vapor,” ANL/RE-95/2 p. 181 (1995).

[8] Hales, J.D. et al., "BISON Theory Manual Release 1.3,” INL/EXT-13-29930, Rev. 3, p. 21 (2016).

[9] Fink, J. K., and L. Leibowitz, “Thermal Conductivity of Zirconium,” Journal of Nuclear Materials 226, (1995). 

[10] Billone, M. C., Y. Y. Liu, E. E. Gruber, T. H. Hughes, and J. M. Kramer, "Status of Fuel Element Modeling Codes for Metallic Fuels," Proceedings of American Nuclear Society International Conference on Reliable Fuels for Liquid Metal Reactors, Tucson, Arizona, September 7-11, 1968.

[11] Kim, Y.S., S.L. Hayes, G.L. Hofman, and A.M. Yacout, "Modeling of Constituent Redistribution in U-Pu-Zr Metallic Fuel,” Journal of Nuclear Materials 359 (2006).

[12] Porter, D.A., and K.E. Easterling, "Phase Transformations in Metals and Alloys," Chapman and Hall, $2^{\text {nd }}$ Edition (1992). 